\title{
DESENHANDO CIDADES
}

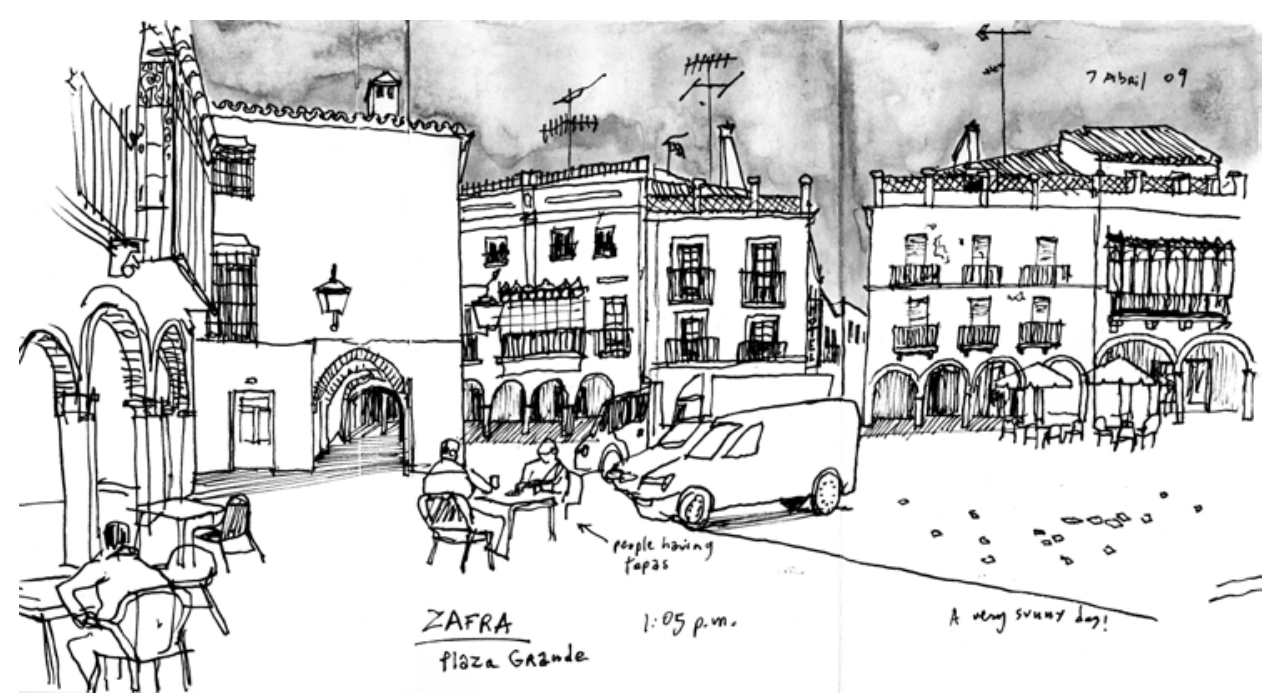

1. Desenho de Gabi Campanario da cidade de Zafra, Espanha. Publicado no seu blog com legenda sobre a experiência de viajar e desenhar no local. Disponível em <http://goo.gl/tgGvr>

\section{CONHECER O MUNDO, UM DESENHO DE CADA VEZ'}

[os objetos] estão sempre "abertos para novos campos de significação", pois "existem perante os olhos que os olham" [...]. "Cada olhar tem a sua própria história, feita de construção intelectual, experiência, sensibilidade e do próprio devaneio em que procura os seus limites"

(Brito, 2009: 4-5).

Para o antropólogo Joaquim Pais de Brito, desenhar é uma forma de conhecer, compreender, se apropriar, narrar, produzir. "Desenhar para ver", escreve ele no catálogo da exposição com desenhos da artista plástica Bárbara Assis Pacheco sobre obras do acervo do Museu Nacional de Etnologia de Lisboa. O desenho é uma das múltiplas linguagens que produzem um conhecimento mais rico sobre tudo que nos cerca. ${ }^{2}$ 
Em novembro de 2007, Gabriel (Gabi) Campanario, espanhol radicado nos EUA como ilustrador-jornalista do jornal The Seattle Times, criou no site Flickr um grupo de postagem de desenhos com o título "urban sketches" [desenhos urbanos]. Um ano depois, a iniciativa deu origem a um blog e, em dezembro de 2009, também à Urban sketchers (USK) - organização sem fins lucrativos e com o objetivo de organizar eventos, levantar fundos e oferecer bolsas para artistas. Além de reunir membros de mais de 50 países, a USK gerou também cerca de 25 blogs locais afiliados, como o USK-Portugal, USK-Indonesia, USK-Argentina etc. O primeiro encontro internacional promovido pela ONG ocorreu em 2010, em Portland, EUA. No ano seguinte, em Lisboa, Portugal, houve um segundo evento, de que participaram cerca de 250 "desenhadores urbanos", entre professores, alunos e palestrantes. ${ }^{3} \mathrm{O}$ "espírito" da USK está sintetizado em seu manifesto, traduzido aqui (por $\mathrm{mim}$ ) de modo ligeiramente resumido:

Desenhamos no local, capturando aquilo que vemos pela observação direta. Nossos desenhos contam a história do que nos rodeia, dos lugares onde vivemos e por onde viajamos. Nossos desenhos são um registro do tempo e do lugar. Somos fiéis às cenas que presenciamos. Usamos qualquer tipo de técnica e valorizamos a diversidade de estilos. Apoiamo-nos uns nos outros e desenhamos em grupo. Compartilhamos nossos desenhos online. Mostramos o mundo, um desenho de cada vez.

A última frase do manifesto tornou-se um símbolo do grupo e um lema. Estampada com destaque em todos os seus blogs - no original We show the world, one drawing at a time -, as palavras chamam a atenção para um fenômeno interessante no mundo atual: conhecer o mundo através dos desenhos.

A expressão "show the world" não quer dizer apenas "mostrar o mundo", e sim explorar e conhecer este mundo, como as muitas traduções do verbo "to show" explicitam: "apresentar, revelar, manifestar, expor, marcar, dar provas de, realçar, atestar, salientar, deixar ver, fazer compreender, demonstrar, tornar visível". ${ }^{4}$

Teresa Carneiro explora tais dimensões, apresentando os desenhos do livro Diários gráficos em Almada - que conta com a participação de vários membros da USK de Portugal e Espanha - como experiências que exprimem um "olhar mais atento", uma "investigação sistemática", uma "atitude de interrogar e redescobrir as mediações e modos de ver o mundo" para, finalmente, "(re) encontrar o mundo pelo desenho". ${ }^{5}$ 


\section{“NÃO SOMOS DESENHADORES PERFEITOS"}

Para Eduardo Salavisa, não ser um "desenhador perfeito" é um valor. A noção de que é possível produzir desenhos sem se autodenominar "artista" (ou profissional do desenho) torna-se central neste universo, como explica:

Os autores dos desenhos dos cadernos expostos não pretendem ser artistas. Se o são, e alguns serão, não foi por isso que participam dessa exposição. O serem muito bons desenhadores, que o são, não foi também por isso que estão aqui. Participam porque têm um hábito: desenharem em cadernos de maneira sistemática, diariamente, diria mesmo, obsessivamente (Salavisa, 2011: 9).

No universo de pessoas que colaboram com o USK, destaca-se um desenhador e blogueiro-chave: Danny Gregory. Este novaiorquino é autor de pelo menos três livros centrais para o mundo dos desenhos em cadernos e para a sua interface online. ${ }^{6}$ Tudo começa em 2003, com a publicação do livro Everyday matters: a memoir, uma autobiografia feita de textos e desenhos, definida em sua contracapa como uma "graphic memoir". ${ }^{7}$ Gregory narra ali a história do acidente que deixou paraplégica a sua esposa Patty e de como o casal seguiu a vida criando o filho Jack, na época do acidente um bebê de apenas dez meses. O sentido da história encontra-se assim resumido na contracapa do livro (em tradução livre):

Num mundo onde nada parecia ter muito sentido, Danny decidiu ensinar a si próprio a desenhar, e o que ele aprendeu foi espantoso. De repente, as coisas tinham cor e valor novamente. O resultado é Everyday matters, um diário de suas descobertas, recuperação e cotidiano na cidade de Nova York. É um livro engraçado, espirituoso e surpreendente, como a própria vida.

Na página 12 da obra, o próprio Gregory narra, com certo suspense: "Então, numa noite, decidi ensinar a mim mesmo a desenhar". A pausa ("numa noite"), o inusitado ("ensinar a mim mesmo") e a habilidade mágica ("desenhar") reúnem todos os ingredientes de um ritual de transformação, onde o herói supera obstáculos e descobre um mundo novo. Em suas próprias palavras: "[...] não importava o que desenhasse"; importava apenas desenhar a partir daquele "lento, cuidadoso e contemplativo olhar" (slow, careful gaze), através do qual aprendeu a valorizar "cada dia" (every day matters) e cada objeto, por mais simples que fosse. Latas de comidas abertas, velhos pares de sapato, uma esquina de Nova York - tudo pode ganhar espaço em seus cadernos de desenhos.

Saul Steinberg, citado por Gregory como uma de suas fontes de inspiração, escreve sobre desenhar como esse processo de conhecimento: "É preciso estabelecer uma cumplicidade com o objeto que se está desenhando, até que se chegue a um conhecimento profundo dele". O desenho de observação, diz o artista, "obriga [o desenhador] a encontrar respostas para perguntas nunca antes formuladas" (Steinberg, 2011:125-126). 
Vários desses elementos aparecem em The creative license - livro mais extenso de Gregory e onde encontramos explícito o objetivo de "celebrar o amadorismo" (contracapa) e fazer do desenho um processo, um meio de descoberta e recuperação de si mesmo, como enfatizam título e subtítulo: "Licença criativa: dando permissão a si mesmo para ser o artista que você realmente é" ("The creative license: giving yourself permission to be the artist you truly are”). Há um jogo de palavras difícil de traduzir, onde os termos license e permission remetem à ideia de se ganhar uma carteira de habilitação (para conduzir automóveis). Ou seja, aprender a desenhar seria como aprender a dirigir. Todos podem. É este o mesmo princípio nas entrelinhas do manifesto USK (que não utiliza a palavra "artista") e explicitamente no texto de Salavisa, citado acima. Na epígrafe do livro de Gregory, não por acaso, lê-se: "Dedicado a você, o artista". Na introdução de An illustrated life, Gregory conversa com o seu leitor:

Espero que eles [os desenhadores deste livro] o encorajem a comprar um pequeno livro de desenho para começar a registrar [desenhar] os conteúdos do seu armário de remédios, seus companheiros de viagem diária de ida e volta para o trabalho, a bagunça na sua mesa. Seja você artista, designer, escritor, músico ou contador, espero que venha a descobrir a riqueza, a aventura e os horizontes infinitos de sua própria vida ilustrada (Gregory, 2008, tradução minha).

Tornar-se um desenhador, neste universo, é uma jornada de autoconhecimento que transforma e confere identidade. Trata-se de desenhos onde os "objetos" não existem em si mesmos; os objetos são sempre "objetos desenhados por alguém". Como nos diz John Berger, o desenho de uma árvore não nos mostra uma árvore, mas "uma árvore-sendo-olhada". Teresa Carneiro completa a ideia afirmando que os desenhos produzidos por estes desenhadores expõem "qualquer coisa de autobiográfico sobre aquele que desenha" e ainda sobre as condições "em que cada desenho foi realizado" - como se revelassem uma "consciência da própria experiência de ver". ${ }^{8}$ 


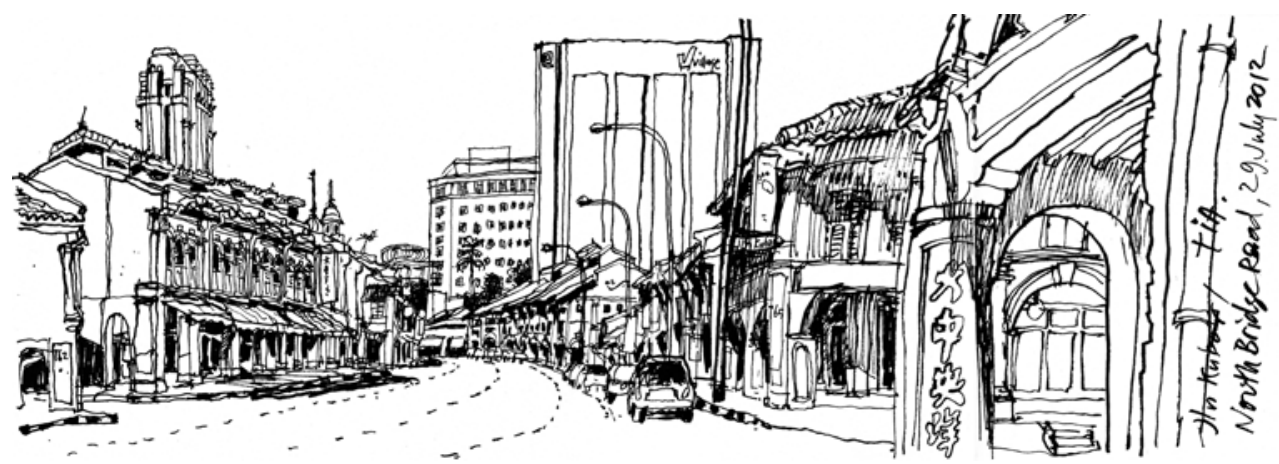

2. Desenho de Tia Boom Sim de North Bridge Road, em Singapura. Publicado no seu Facebook. Disponível em <http://goo.gl/HSCYy>

\section{DESENHANDO CIDADES}

Desenhar uma cidade não é apenas capturá-la no papel. É realmente conhecê-la, senti-la, torná-la sua Nina Johansson, correspondente do blog Urban Sketchers, em Estocolmo, Suécia.

Na obra de Danny Gregory, a temática dos desenhos surge ampla e com uma forte dimensão de observação do universo privado: objetos pessoais, animais de estimação, parentes, amigos, autorretratos. Ao mesmo tempo, desde Everyday matters, a cidade de Nova York mantém-se um personagem forte na sua identidade de desenhador, uma das quatro "mecas criativas" do mundo (ao lado de Los Angeles, Paris e Londres); e é para lá que os seus leitores devem seguir em busca de ideias e pessoas estimulantes. Seus próprios livros, cadernos e publicações online estão recheados de desenhos de Nova York, bem como de muitas outras cidades por onde passou em viagens.

No universo de observação dos urban sketchers, como o próprio nome diz, é o desenho do espaço urbano o ponto central e valorizado. A relação do desenhador com a sua própria cidade ou com as cidades por onde viaja constitui uma das características que singulariza esse projeto. Os nomes das cidades observadas encontram-se nos títulos dos blogs, das páginas, dos livros e na maioria das legendas dos desenhos do universo USK. Todo o encontro internacional do USK, em Lisboa, organizou-se em torno da ideia de se "desenhar a cidade". Seu caderno tinha um desenho de Lisboa na capa, um mapa da cidade no verso e uma programação, em que todos os workshops foram denominados a partir dos locais onde seriam feitos os desenhos.

A coluna e o blog de Gabi Campanario chamam-se "Seattle Sketcher" e têm como objetivo ser um "diário ilustrado" da vida na região. Além dos desenhos "no local", o jornalista-ilustrador escreve sobre o tema desenhado, conta 
a sua história e entrevista pessoas relacionadas ao assunto (agentes do poder público, habitantes da cidade, comerciantes). O modelo é a reportagem jornalística no estilo imagem-texto, mas acrescido da dimensão artesanal e criativa do desenho, com referências às escolhas de cores, aos materiais e a outros elementos do mundo das artes.

Dezenas de outros urban sketchers encontram na cidade o principal tema de seus desenhos. Paul Heaston, por exemplo, destacou-se no grupo por seu projeto de desenhar todos os prédios da rua principal de Bozeman, no estado de Montana, Estados Unidos. Pete Scully, presente nos dois encontros internacionais do USK (até 2011), vem desenhando as principais ruas da cidade de Davis, California, num caderno Moleskine, em formato conhecido como "japonês" (por suas páginas unidas pelas laterais umas às outras). Nina Johansson, cuja citação destaquei no início desta seção, foi professora de um workshop no encontro USK de Lisboa e vê nas cenas de rua da cidade de Estocolmo, Suécia, um de seus temas favoritos.

No evento de 2011, em Portugal, as seis palestras oferecidas relacionavam-se ao tema do desenho em meio urbano. Ruth Rosengarten (sobre a qual falarei mais adiante) refletiu sobre a história e os debates acadêmicos em torno do tema. James Richards destacou a revalorização do desenho de observação, feito à mão, nos projetos de comunicação, arquitetura e entretenimento. Matthew Brehm discorreu sobre como ensinar alunos de arquitetura a desenhar "no local", valorizando vários dos elementos presentes no manifesto USK. Antonio Jorge Gonçalves contou do projeto de viagens que o levou a desenhar passageiros do metrô em dez cidades do planeta, gerando o livro Subway Life. Já Tia Boom Sim falou sobre como ela e o grupo de desenhadores do USK-Cingapura acabaram desencadeando um processo de "redescoberta" e "revalorização" de um bairro da cidade, através do desenho. Simoneta Capecchi mostrou as imagens e os bastidores da realização do projeto "O terremoto de Aquila: uma reportagem coletiva". Diante do prolongamento da tragédia, que resultou em 300 mortos e 1.600 feridos, e tornou Aquila (Itália) uma cidade totalmente evacuada por mais de um ano, um grupo resolveu desenhar o local e, através dos desenhos, contar a sua história e a de seus habitantes. ${ }^{10}$

\section{DISPOSITIVOS PARA DESENHAR}

Para desenhar a cidade, uma das marcas do universo USK é a realização de desenhos em cadernos. Podem ser pequenos, em branco, quadrados, em estilo japonês, de marcas famosas (como o Moleskine), feitos à mão ou mesmo bastante específicos, como cadernos de contabilidade antigos - que se tornaram um símbolo facilmente identificado com Lapin, apelido de Julien Fassel, ilustrador francês radicado em Barcelona, membro do board da USK e desenhador admirado pelos urban sketchers de todo o mundo. 
Um caderno com textos e desenhos, escreve Gregory (2008), pode tornar-se o seu "ombro amigo" e o seu "terapeuta", mas muito mais do que isso. Em Creative license, lista para os seus leitores pelo menos doze motivos a favor da produção de desenhos em diários: são compactos, portáteis, baratos, pessoais, úteis, cumulativos, familiares, estimulam o desenho com o "lado direito do cérebro", válvula de escape, forma de arte, forma de meditação, privado ou público, facilita esconder os erros. "Detestou seu desenho?”, brinca Gregory, "vire a página e comece de novo". ${ }^{11}$

Além dos princípios já levantados - "desenhar para ver", "não ser um desenhador perfeito", "desenhar a cidade" e utilizar cadernos como suporte para os seus desenhos -, o universo dos urban sketchers (delimitado aqui através de seu manifesto, dos blogs e de uma seleção de obras representativas) está repleto de "dispositivos" que estabelecem regras e condições de execução dos desenhos.

Utilizo o conceito de "dispositivo" tal como na definição do cinema-documentário de João Salles, explicada por Arbel Griner. Dispositivo seria, então, “a 'regra', a 'prisão', os 'limites' que o documentarista se auto-impõe ao fazer um filme. [...] sua maneira de enquadrar o mundo" (Griner, 2010:46). Os desenhos dos urban sketchers, do mesmo modo, não são "simplesmente" desenhos: são "enformados" por uma certa "visão de mundo" e constituem em si mesmo um "mundo da arte", nos termos de Becker (1982). Há delimitações do lugar de quem vê (on location), do uso da observação direta (por contraste com o desenho de memória), da busca por uma narrativa (contar uma história a partir do mundo observado) e da oferta de um contexto (do tempo e do local). Há uma base moral (ser truthful, fiel àquilo que se observa) e uma filosófica ("Mostrar o mundo, desenho a desenho" poderia ser comparado ao dito chinês: "A jornada de mil milhas começa com um passo"). Há um respeito à diversidade e aos estilos individuais, bem como um princípio de não distinção entre artista e não-artista, implícito na defesa do caderno (e não da galeria de arte) e da sua identidade coletiva e não comercial (apoiamo-nos uns nos outros, desenhamos em grupo e compartilhamos nossos desenhos online).

A partir destes dispositivos gerais, é muito frequente que cada desenhador estabeleça os seus próprios, tais como desenhar "todos os dias" (vários, em Salavisa, 2008); desenhar durante um mês apenas as "roupas do seu armário" (Gregory, 2006); desenhar "sempre em pé", para nunca se sentir "confortável demais" (M. Brehm); ${ }^{12}$ ou desenhar qualquer coisa "em menos de 30 minutos" (Steel, 2010) ou em mídias muito particulares, como os já mencionados "cadernos de contabilidade antigos" de Lapin.

Como nos documentários de Salles, em seu projeto Subway Life, Gonçalves (2010) estabeleceu uma lista de dispositivos para si próprio: desenhar pessoas no metrô; desenhar as pessoas em corpo inteiro, mas não o ambiente em torno; não "selecionar" um personagem do desenho: obrigar-se a desenhar o 
passageiro que estivesse à sua frente (para driblar a ideia do "desejo" pelo objeto desenhado); desenhar apenas em "cadernos quadrados" ("paixão" pessoal, depois abandonada, segundo o autor, quando chegou a Nova York e descobriu "passageiros grandes demais" para aquele formato); desenhar em metrôs de dez cidades diferentes; e desenhar por todas as linhas do metrô escolhido, em todos os horários possíveis de seu funcionamento, em sessões diárias de três a seis horas cada. ${ }^{13}$

Um dos objetivos desta investigação é aprofundar o entendimento de tais dispositivos, aqui apenas esboçados. Acredito que seja este um bom caminho para se compreender como os desenhadores urbanos se relacionam com a cidade através dos desenhos, ou - também poderíamos perguntar a nós mesmos - de que modo esses desenhadores constroem os seus desenhos através das formas como "enquadram" a cidade.

\section{ANTROPOLOGIA, CIDADE, DESENHO}

A possibilidade de transformar o USK num universo de pesquisa ganhou densidade quando li o texto de Oscar Wilde, The decay of lying: an observation. Nesse pequeno ensaio, escrito sob a forma de diálogos, o autor escreveu uma de suas famosas frases: “... a vida imita a arte, muito mais do que a arte imita a vida" (“... life imitates art far more than art imitates life”). A máxima, de tão conhecida, não desperta muita atenção. Uma vez colocada em seu contexto, isto é, na argumentação dos personagens de Wilde, revela, no entanto, uma abordagem profundamente antropológica da relação entre a produção artística e a vida social:

As coisas são porque nós as vemos, e o que vemos, e como vemos, depende de como a Arte nos influenciou. [...] As pessoas veem fogs não porque existam fogs, mas porque os poetas e os pintores lhes ensinaram o misterioso encanto dos seus efeitos. Deve ter havido fogs em Londres por séculos. [...] Mas ninguém os via, e, portanto, não sabíamos nada sobre eles. Eles não existiam até que a Arte os inventou. ${ }^{14}$

Van Gogh fala-nos da dificuldade de se abrir caminho pelo "muro invisível" que se interpõe entre o que artista vê (e sente) e o que o seu desenho produz: "O que é desenhar? Como conseguimos? É a ação de abrir caminho através de um muro de ferro invisível, que parece encontrar-se entre o que sentimos e o que podemos" (Van Gogh, 2002: 102).

"A exatidão não é a verdade", diz Matisse em seus Escritos e reflexões sobre arte. É preciso levar em conta o "sentimento profundo do artista perante os objetos que escolheu", sem supor que uma "reunião dos detalhes exatos" e "pacientemente agrupados" permita recriar a natureza num desenho (Matisse, 2007: 192).

Como Matisse e Van Gogh, Paul Klee também refletiu sobre a necessidade de o artista sentir, selecionar, achar o seu caminho: 


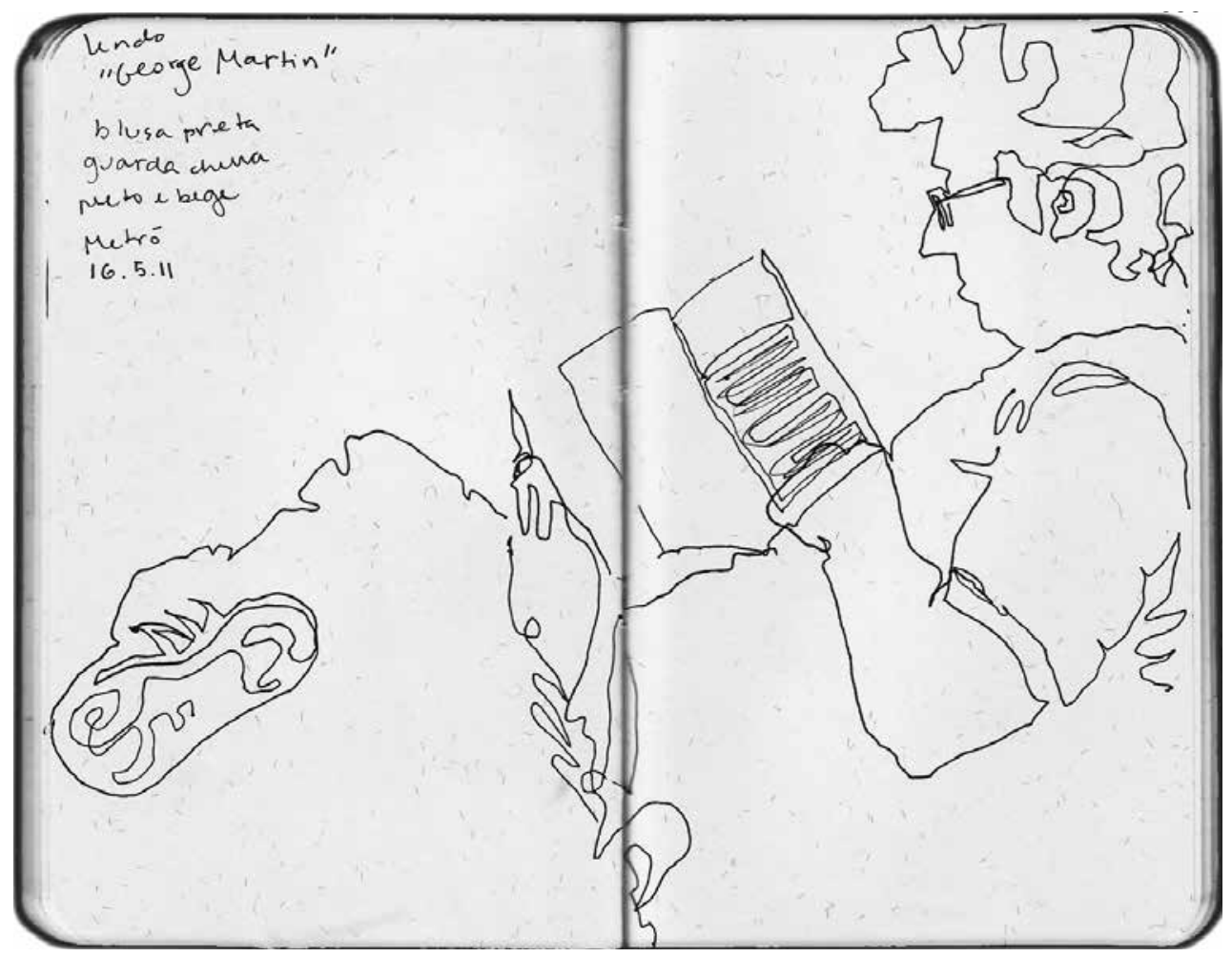

3. Desenho de Karina Kuschnir de leitor no metrô do Rio de Janeiro.

A arte não reproduz o visível, mas torna visível. [...] Tem de haver alguma região comum aos espectadores e artistas, na qual é possível uma aproximação mútua, e onde o artista não precisa aparecer como algo à parte, mas sim como uma criatura que, como os senhores, foi lançada sem aviso num mundo multiforme e, como os senhores, tem que achar seu caminho, por bem ou por mal (Klee, 2001: 52, grifo meu).

Arrisco dizer que transpor o "muro invisível" de Van Gogh, o "sentimento profundo" de que nos fala Matisse e o caminho para "tornar visível" o "mundo multiforme" de Klee são caminhos possíveis para se entender o olhar do desenhador sobre a cidade; um olhar que produz, recorta, significa a cidade por meio do desenho.

Essa busca de significados para a cidade - e para a experiência de se viver em cidades - situa-se no cerne das fontes desta pesquisa. Seleciono três autores-chave no universo dos urban sketchers: Gabriel Campanario (2012), Danny Gregory $(2003,2006,2008)$ e Eduardo Salavisa (2008, 2010a, 2010b, 2011) - autores e/ou organizadores de coletâneas representativas que congregam dezenas de outros desenhadores, de variadas origens e estilos. ${ }^{15}$ Já Gonçalves (2010) e Steel (2010) surgem como dois exemplos diferentes de obras que reproduzem cadernos de desenhos, sendo o primeiro fruto de um grande projeto, e o segundo, um livreto impresso e comercializado pela própria autora. 
Tais publicações (sempre em interação com os seus respectivos blogs, flicrks e facebooks) constituem fontes para a pesquisa, mas também dialogam com o campo de reflexão acadêmico. É especialmente rica a introdução de Salavisa (2008) acerca do universo dos cadernos de desenho, dos cadernos de viagens e dos diários gráficos ao longo da história e por diferentes tipos de artistas, como Eugène Delacroix, Edward Hopper, Frida Kahlo, Pablo Picasso, Le Corbusier, entre outros. ${ }^{16}$ Nesse texto, bem como no paper de Ruth Rosengarten - historiadora da arte, além de artista e urban sketcher -, há uma bibliografia acadêmica selecionada, e são apontadas muitas questões que conversam com os objetos desta pesquisa. A autora destaca alguns temas centrais no projeto USK: o desenho de observação "no local" (on location), o desenho como "testemunho" e o desenho feito em "perambulação urbana". E completa (em tradução ligeiramente resumida por $\mathrm{mim})$ :

Historicamente, o sketchbook se situa em algum lugar no espectro entre a objetividade e a subjetividade. É um companheiro para o viajante e um instrumento para o etnógrafo, registrando não apenas seu entorno, urbano e natural, mas também as vidas e os hábitos dos nativos [...].

Rosengarten sugere a aproximação entre desenhadores, historiadores e antropólogos que realizam uma "observação detalhada do cotidiano" (everyday life) da cidade. Para a autora, é central a reflexão de Michel de Certeau: aquele que perambula pelas ruas pode perder a visão do todo, mas realiza uma exploração corporal e sensitiva, apropriando-se de maneira nova dos espaços da cidade. ${ }^{17}$

Também desenhador, o antropólogo Manoel João Ramos afirma que desenhar realiza uma oportunidade de "participar de um mundo" que não é seu, criando-se ordens "imaginárias" e organizando-se na memória as "experiências vividas". Além disso, o ato de desenhar, por contraste ao de fotografar ou filmar, permitiria um diálogo mais aberto com as "pessoas com as quais o viajante se defronta". Para Ramos, no caso do etnógrafo, o gesto de desenhar é especialmente importante, pois se torna um convite ao nativo "para que olhe, para que dialogue com ele, para que lhe conceda o estatuto de ser humano". ${ }^{18}$

No Brasil, o projeto de desenhar para conhecer a cidade ganha força na fala da arquiteta e ilustradora paulistana Paula Caffé. Desenhar "no local" torna-se uma forma nova de "ver" e se apropriar da cidade:

Permanecer no local faz muita diferença no desenho: pela movimentação, pelos pedestres, pelo clima. [...] No livro da Avenida Paulista eu resgatei essa metodologia de desenhar na rua. [...] é importante a gente desenhar a nossa cidade, no sentido de pôr no mapa. [...] Eu espero que meu desenho instigue as pessoas a desenharem a sua cidade. Porque eu acho que o desenho é uma forma de conhecimento. Ao desenhar, você acaba conhecendo muitas coisas; acaba descobrindo muitas coisas. Não só coisas interiores, suas, como coisas que estão aí, para serem desenhadas (grifos meus). ${ }^{19}$ 


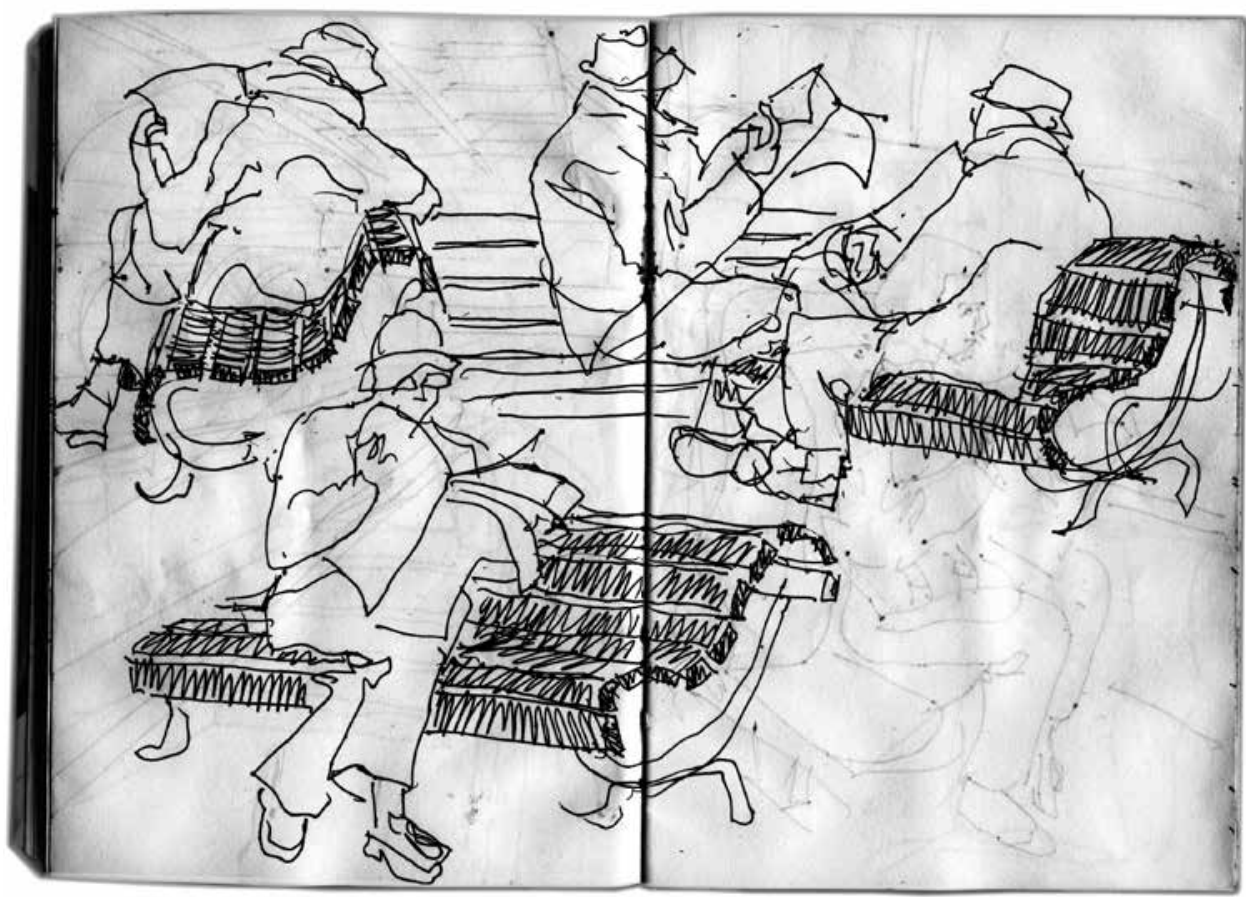

4. Desenho de Eduardo Salavisa de leitores no Jardim da Estrela, Lisboa, publicado em seu blog com comentários sobre o local. Disponível em <http://goo.gl/SEKZY>

Projetos contemporâneos, exclusivamente de desenho em (ou de) cidades, como Av. Paulista, não são muito numerosos na bibliografia sobre o tema, mesmo se levarmos em conta o rico acervo ficcional - às vezes também documental - dos romances gráficos (graphic novels) que produziram volumes como Nova York: a vida na grande cidade (Eisner, 2009).

Sobre o Rio de Janeiro, com a sua longa tradição de cidade desenhada, o número de obras é incalculável. Mas trabalhos recentes são poucos. Rio de Janeiro: les carnets de Voyage de Jano é, sem dúvida, uma obra especial, bem como o livro Quando rua vira casa (Santos \& Vogel, 1981) onde fotos e desenhos se misturam numa riquíssima interação com o texto dos pesquisadores. Temos também algumas publicações realizadas a partir das exposições de desenhos de humor, charges e ilustrações, como, por exemplo, em Caruso (2009). Fontes como essas são uma referência importante para o desenvolvimento de uma paisagem semântica na história recente da cidade (1975-2011). ${ }^{20}$

Merecem atenção especial os trabalhos sobre J. Carlos, por tratarem especificamente da relação entre o desenhador (ilustrador) e a cidade do Rio de Janeiro: O bonde e a linha: um perfil de J. Carlos (Loredano, 2002) e O Rio de J. Carlos (Loredano \& Ventura, 1998). Os autores nos mostram, através de textos e imagens, como se foram construindo as influências mútuas entre a sociedade que se urbanizava e a sua expressão nos desenhos de J. Carlos. Os tipos das 
ruas, os homens públicos, os bairros, os automóveis, a praia, o lazer, o futebol, as construções... tantos objetos e temas sendo desenhados numa abordagem bastante próxima do que Julia O’Donnell (2008) chamou de “temperamento etnográfico". Aproximam-se também do olhar sobre a cidade que Gilberto Velho buscava em sua obra. Em Antropologia urbana (Velho, 1999), Cordeiro \& Costa mostram jogos de disputas em torno dos bairros, o que acaba por revelar "variadas mitografias, imagens e narrativas que cada cidade escolhe para se vestir". No mesmo livro, Castro (1999) mostra-nos, através da transformação das representações cartográficas do Rio de Janeiro, diferentes formas de o turista experimentar a cidade, feitas de "narrativas e imagens muitas vezes dissonantes e conflitivas entre si", como em distintas "províncias de significado", nos termos de Alfred Schutz.

É com este espírito, de experimentar e observar narrativas dissonantes, que Saul Steinberg recorda, com humor, a atividade de desenhar as ruas de Nova York:

Em 1950, fiz desenhos mais ou menos a partir da observação de paisagens americanas, ruas americanas, coisas que já não existem mais. Na época, não havia ninguém que se interessasse por essas coisas; os pintores americanos procuravam lugares, ângulos que se parecessem com a "verdadeira pintura". Mesmo numa main street, buscavam uma nesga de pintura inglesa ou alguma coisa de Rembrandt ou de Vermeer. Havia vários pintores em Nova York - Reginald Marsh, por exemplo - que buscavam na rua 14 alguma coisa à maneira de Hogarth ou de Rubens (Steinberg, 2010:132-33).

Sendo eu mesma desenhadora (Kuschnir, 2012) e antropóloga, vislumbrei no universo dos urban sketchers a possibilidade de realizar um trabalho de campo em que o desenho e a cidade se entrelaçassem. O projeto, aprovado pelo CNPq e iniciado em 2012, teve a sorte de ver a criação do Urban sketchers no Brasil, com base em São Paulo e com representantes em diversas cidades do País.

A pesquisa tomará esse universo de desenhadores e suas fontes como ponto de partida, mas pretende explorar outros grupos que desenham em áreas urbanas e em regiões de favelas, hoje mais comumente chamadas por seus moradores de "comunidades".

São muitas perguntas a responder. Quem desenha qual cidade? Que narrativas sobre a cidade são produzidas? Que áreas, temas e elementos são selecionados, recortados, desenhados? Como se dão as relações entre desenhadores e a cidade, por meio de dispositivos e percursos para a produção de seus registros gráficos? Quais significações emergem desses desenhos? Quais as continuidades e rupturas das construções gráficas e simbólicas sobre a cidade frente à paisagem semântica hegemônica, construída ao longo da sua história, no caso específico do Rio de Janeiro? Estes questionamentos formam o meu ponto de partida para a pesquisa etnográfica. 


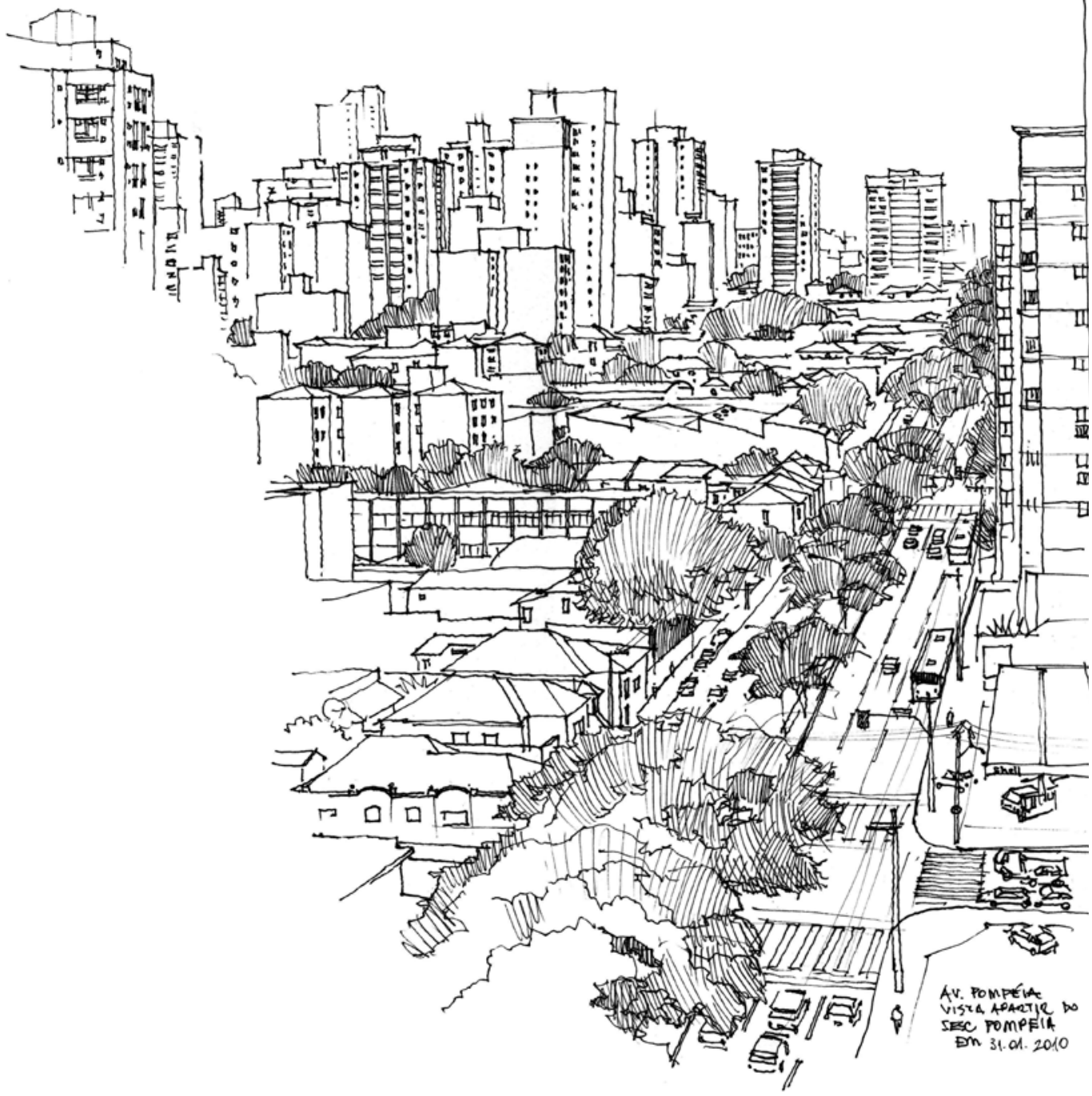

5. Desenho de Eduardo Bajzek da Avenida Pompéia, São Paulo, publicado em seu blog com comentários sobre sua realização. Disponível em <http://goo.gl/RfHc5> 
Karina Kuschnir é professora do Departamento de Antropologia Cultural e do Programa de Pós-Graduação em Sociologia e Antropologia (PPGSA) da Universidade Federal do Rio de Janeiro (UFRJ). É autora de Antropologia da política (2007) e co-organizadora (com Gilberto Velho) de Pesquisas urbanas: desafios do trabalho antropológico (2003), entre outras publicações. Desenvolve atualmente os projetos "História audiovisual das ciências sociais nos países da CPLP" e "Desenhando a cidade: um estudo etnográfico no Rio de Janeiro" (ambas financiadas pelo Conselho Nacional de Desenvolvimento Científico e Tecnológico - CNPq). 


\section{NOTAS}

1 Este texto faz parte de um projeto de pesquisa e tem outras versões (Kuschnir, 2011). Agradeço a Gilberto Velho (in memoriam) por todo o apoio e companheirismo nesse empreendimento. Um agradecimento muito especial também a Gabi Campanario, Eduardo Salavisa, Tia Boom Sim e Eduardo Bajzek que autorizaram a reprodução de seus desenhos neste artigo.

2 Todas as citações estão em Brito (2009: 4 e 5). Sobre a origem e a pluralidade de significados da palavra "desenhar", ver Gomes (1996).

3 Informações detalhadas sobre a USK estão disponíveis em $<$ www.urbansketchers.org $>$.

4 Cambridge Advanced Learner's Dictionary (software), Cambridge University Press, v. 1, 2003.

5 Esta e as demais citações de Teresa Carneiro estão em seu texto "Desenhar o olhar sobre o mundo", publicado em Salavisa (2011).

6 Seus três livros principais estão citados na bibliografia. Gregory também foi o criador e moderador do grupo de discussão online fundado em 2004, hoje com mais de 4 mil membros, no site Yahoo Groups. Desde 2011, seu blog está em <www.dannygregory.com>.

7 Referência ao conceito de "graphic novel" - termo consagrado para livros de arte sequencial, com temas mais densos, para adultos, que não se enquadram na categoria "histórias em quadrinhos". Sobre tais termos, ver o capítulo 7 de Quadrinhos e a arte sequencial, de Will Eisner (1999).

8 O trecho de Berger (2005) é citado por Teresa Carneiro em Salavisa (2011).

9 No original: "Drawing a city isn't just capturing it on paper, it's really about getting to know it, to feel it, to make it your own", publicada na seção "About us", no blog Urban Sketchers. Disponível em <http://www.urbansketchers.org/p/about-usk.html>.

10 Todos os links para os blogs dos referidos palestrantes podem ser encontrados em <http://symposium.urbansketchers.org/>. 
11 A expressão "desenhar com o lado direito do cérebro" tornou-se famosa pelo título do livro de Betty Edwards (2005) e significa, resumidamente, realizar um desenho de observação despindo-se dos "conceitos" conhecidos intelectualmente sobre os objetos observados. A referência é bastante citada em livros e blogs no universo USK.

12 Informação oral, dada por Matthew Brehm em seu workshop, no II Symposium USK, em Lisboa.

13 Dispositivos apresentados por António Jorge Gonçalves, em sua palestra no II Symposium USK, em Lisboa.

14 Tradução livre a partir do original (Wilde, 1889). Agradeço a Alberto Goyena pela indicação desse texto.

15 Em 2011, foi publicada outra obra importante do gênero, organizada por Cathy Johnson (2011), com colaboração de vários dos desenhadores aqui mencionados.

16 Outro exemplo, publicado no Brasil, são os Cadernos de viagem, de Debret ([1816] 2006).

17 As ideias estão em Certeau (2000, citado por Rosengarten, 2011).

18 O texto de Manoel João Ramos está publicado em Salavisa (2011: 152-153). Espero poder desenvolver uma aproximação entre esse conceito de "experiência vivida" através do desenho e o de "teoria vivida" através da etnografia, tal como proposta por Peirano (2006).

19 Depoimento sobre o livro Av. Paulista (Caffé, 2009) para o site da Editora Cosac Naify. Disponível em <http://goo.gl/ mlNgu>. Caffé é também autora de uma premiada coluna, intitulada "Cidade nua", com desenhos e textos sobre a cidade de São Paulo, publicada na revista do jornal Folha de S. Paulo, entre 1991 e 1994.

20 Ver Goslin (2010), Rebelo (2007) e o livro de Jano em Michel (2001). Há também um recente livro sobre sketch books, editado em São Paulo, mas pouco voltado para o desenho da cidade (Almeida \& Bassetto, 2010). No Rio de Janeiro, existem alguns guias turísticos ilustrados apenas com desenhos - mas são publicações que, pela sua própria finalidade, se distanciam muito dos princípios dos urban sketchers. 


\section{REFERÊNCIAS BIBLIOGRÁFICAS}

Almeida, Cézar de \& Bassetto, Roger. Sketchbooks - As páginas desconhecidas do processo criativo. São Paulo: POP, 2010. Becker, Howard S. Art worlds. Berkeley/Los Angeles/Londres: University of California Press, 1982. (Edição portuguesa: Mundos da arte: edição comemorativa do $25^{\circ}$ aniversário - Revista e aumentada. Trad. Luís San Payo. Lisboa: Livros Horizonte, 2010.)

Berger, John. Drawn to that moment. In: Savage, Jim (org.). Berger on drawing - essays. Cork: Ireland Occasional Press, 2005.

Brito, Joaquim Pais de (org.). Desenhar para ver. Catálogo da exposição "Desenhar para ver: o encontro de Bárbara Assis Pacheco com as galerias da Amazónia". Lisboa: Museu Nacional de Etnologia, 2009.

Caffé, Carla. "Cidade Nua" (Coluna semanal de desenhos da cidade). Folha de S. Paulo, Revista da Folha, 1991-1994.

Av. Paulista (Coleção Ópera Urbana). São Paulo: Cosac Naify/SESC-SP, 2009.

Campanario, Gabriel (org.) The art of urban sketching: Drawing on location around the world. Beverly, MA: Quarry Books, 2012. Caruso, Eliana (org.). $2^{\circ}$ Festival Internacional de Humor do Rio de Janeiro: A arte de desdesenhar. Rio de Janeiro: Ministério da Cultura, 2009.

Castro, Celso. Narrativas e imagens do turismo no Rio de Janeiro. In: Velho, Gilberto (org.). Antropologia urbana. Cultura e sociedade no Brasil e em Portugal. Rio de Janeiro: Zahar, 1999, p. 80-87.

Certeau, Michel de. A invenção do cotidiano. Artes do fazer. Petrópolis: Vozes, 2000, vol. 1.

Cordeiro, Graça Índias \& Costa, António Firmino da. Bairros, contexto e intersecção. In: Velho, Gilberto (org.). Antropologia urbana: cultura e sociedade no Brasil e em Portugal. Rio de Janeiro: Zahar, 1999, p. 58-79.

Debret, Jean-Baptiste. Caderno de viagem. Julio Bandeira (org.). Rio de Janeiro: Sextante, 2006.

Edwards, Betty. Desenhando com o lado direito do cérebro. Rio de Janeiro: Ediouro, 2005. 
Eisner, Will. Quadrinhos e a arte sequencial. Rio de Janeiro: Martins Fontes, 1999.

. Nova York: a vida na grande cidade. São Paulo: Companhia das Letras (Quadrinhos na Cia.), 2009.

Gomes, Luiz Vidal Negreiros. Desenhismo. Santa Maria: Ed. Universidade Federal de Santa Maria, 1996.

Gonçalves, António Jorge. Subway life/Vida subterrânea. Lisboa: Assírio e Alvim, 2010.

Goslin, Priscilla Ann \& Carneiro, Carlos. How to be a Carioca: the alternative guide for the tourist in Rio. 3. ed. Rio de Janeiro: TwoCan, 2010.

Gregory, Danny. Everyday matters: a memoir. Nova York: Hyperion, 2003.

. The creative license: giving yourself permission to be the artist you truly are. Nova York: Hyperion, 2006.

An illustrated life: drawing inspiration from the private sketchbooks of artists, illustrators and designers. Cincinnati, Ohio: How Books, 2008.

Griner, Arbel. A estética da ética: uma análise do cinema documentário de Eduardo Coutinho, Eduardo Escorel. Dissertação de Mestrado. PPGSA/Universidade Federal do Rio de Janeiro, 2010.

Johnson, Cathy. Artist's journal workshop: Creating your life in words and pictures. Cincinnati, Ohio: North Light Books, 2011. Klee, Paul. Sobre a arte moderna e outros ensaios. Rio de Janeiro: Zahar, 2001.

Kuschnir, Karina. Drawing the city: A proposal for an ethnographic study in Rio de Janeiro. Vibrant, 2011, 8/2, p. 608-642.

. Desenho Cais do Sodré - captar o movimento. In: Salavisa, Eduardo (coord.). Urban sketchers em Lisboa: desenhando a cidade. Lisboa: Quimera, 2012, p. 70. (Edição bilíngue: Urban sketchers in Lisbon: drawing the city).

Loredano, Cássio (org.) \& Ventura, Zuenir (texto). O Rio de J. Carlos. Rio de Janeiro: Lacerda, 1998.

. O bonde e a linha: um perfil de J. Carlos. São Paulo: Capivara, 2002.

Matisse, Henri. Matisse: escritos e reflexões sobre arte. In: Fourcade, Dominique (org.). São Paulo: Cosac Naify, 2007. 
Michel, Albin. Rio de Janeiro: les carnets de voyages de Jano. Paris: Sefam, 2001.

O'Donnell, Julia. De olho na rua: a cidade de João do Rio. Rio de Janeiro: Zahar, 2008.

Peirano, Mariza. A teoria vivida. Rio de Janeiro: Zahar, 2006.

Rebelo, Marques. Guia antiturístico do Rio de Janeiro (com ilustrações de Jaguar e prefácio de Millôr). Rio de Janeiro: Desiderata/Batel, 2007.

Rosengarten, Ruth. Passing by, stopping, walking on: urban sketching in context. Texto apresentado no II International Urban Sketching Symposium. Lisboa, 2011. Disponível em <http://goo.gl/IARWy $>$.

Salavisa, Eduardo (org.) Diários de viagem: desenhos do quotidiano - 35 autores contemporâneos. Lisboa: Quimera, 2008. . (org.). Diário de viagem em Lisboa. Edição Bilíngue. Lisboa: Quimera, 2010a.

Diário de viagem em Cabo Verde. Edição Bilíngue. Lisboa: Quimera, 2010b.

(org.). Diários gráficos em Almada - "Não somos desenhadores perfeitos". Almada: Câmara Municipal/Museu da Cidade, 2011.

(org.) Urban sketchers em Lisboa: desenhando a cidade. Lisboa: Quimera, 2012. (Edição bilíngue: Urban sketchers in Lisbon: drawing the city).

Steel, Liz. From my sketchbooks. Impresso por Blurb.com, 2010.

Steinberg, Saul. Reflexos e sombras (com a colaboração de Aldo Buzzi). São Paulo: Instituto Moreira Salles, 2011. Van Gogh, Vincent. Cartas a Théo. Pierre Ruprecht (org.) Porto Alegre: LP\&M, 2002.

Velho, Gilberto. A utopia urbana: um estudo de antropologia social. Rio de Janeiro: Zahar, 1973.

Santos, Carlos Nelson F. \& Vogel, Arno (orgs.). Quando a rua vira casa: a apropriação de espaços de uso coletivo em um centro de bairro. 2. ed. Rio de Janeiro: Ibam/Finep, 1981. Wilde, Oscar. The Decay of Lying: an Observation, 1889. Disponível em <http://goo.gl/c2CHq>. Acesso em 5 set. 2012. 


\section{Resumo:}

Notas sobre a pesquisa "Desenhando a cidade", que teve início em março de 2012. Apresento a trajetória e os valores de um grupo internacional que se autodenomina "desenhadores urbanos" (urban sketchers). Trata-se de um projeto que valoriza o desenho como uma forma de olhar, conhecer e registrar a experiência de se viver em cidades. Faço algumas aproximações entre desenho e antropologia, bem como sobre a sua relação com as cidades e com o Rio de Janeiro, em particular. Que narrativas sobre a cidade são produzidas? Que áreas, temas e elementos são selecionados, recortados, desenhados? Como se dão as relações entre desenhadores e a cidade, por meio de dispositivos e percursos para a produção de seus registros gráficos? Estes são alguns dos questionamentos que formam o meu ponto de partida para a pesquisa etnográfica.

\section{Abstract:}

Notes on the research "Drawing the city", which began in March 2012. I begin by mapping the production of an international group calling themselves "urban sketchers" whose collective project extols drawing as a form of looking, knowing and registering the experience of living in cities. Next I show the connections between drawing and anthropology, as well as their relation to cities and to Rio de Janeiro in particular. What narratives about the city are produced? What areas, themes and elements are selected, cut, drawn? These are some of the questions that form the starting point for my ethnographic research.
Palavras-chave:

Desenho; Cidade; Antropologia; Desenhadores urbanos; Rio de Janeiro.

Keywords:

Drawing; City; Anthropology; Urban sketchers; Rio de Janeiro. 